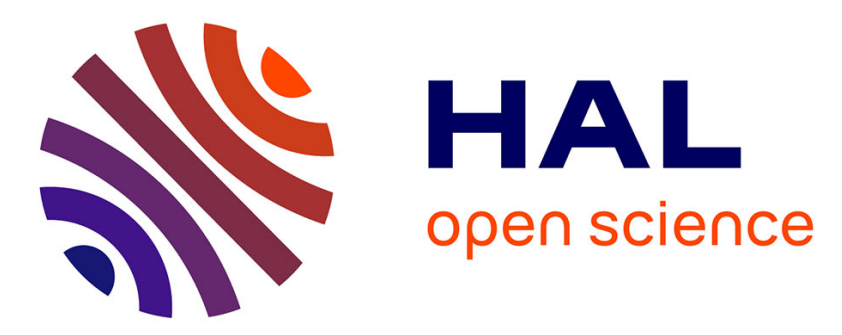

\title{
Intercomparison of active personal dosemeters in interventional radiology
}

I. Clairand, L. Struelens, Jean-Marc Bordy, Josiane Daures, J. Debroas, Marc

Denozière, L. Donadille, Jean Gouriou, C. Itié, P. Vaz, et al.

\section{- To cite this version:}

I. Clairand, L. Struelens, Jean-Marc Bordy, Josiane Daures, J. Debroas, et al.. Intercomparison of active personal dosemeters in interventional radiology. RADIATION PROTECTION DOSIMETRY, 2008, 129 (1-3), pp.340-345. 10.1093/rpd/ncn083 . hal-03105002

\section{HAL Id: hal-03105002 \\ https://hal.science/hal-03105002}

Submitted on 23 Feb 2022

HAL is a multi-disciplinary open access archive for the deposit and dissemination of scientific research documents, whether they are published or not. The documents may come from teaching and research institutions in France or abroad, or from public or private research centers.
L'archive ouverte pluridisciplinaire HAL, est destinée au dépôt et à la diffusion de documents scientifiques de niveau recherche, publiés ou non, émanant des établissements d'enseignement et de recherche français ou étrangers, des laboratoires publics ou privés. 


\title{
INTERCOMPARISON OF ACTIVE PERSONAL DOSEMETERS IN INTERVENTIONAL RADIOLOGY
}

Isabelle Clairand ${ }^{1}$, Lara Struelens ${ }^{2}$, Jean-Marc Bordy ${ }^{3}$, Josiane Daures ${ }^{3}$, Jacques Debroas ${ }^{1}$, Marc Denozières ${ }^{3}$, Laurent Donadille ${ }^{1}$, Jean Gouriou ${ }^{3}$, Christian Itié ${ }^{1}$, Pedro Vaz ${ }^{4}$ and Francesco d'Errico ${ }^{5}$.

${ }^{1}$ IRSN, France; ${ }^{2} \mathrm{SCK} \cdot \mathrm{CEN}$, Belgium; ${ }^{3} \mathrm{CEA}-\mathrm{LNHB}$, France; ${ }^{4} \mathrm{ITN}$, Portugal; ${ }^{5}$ Università degli Studi di Pisa, Italy and Yale University, USA.

Short running title: Use of APDs in interventional radiology

\begin{abstract}
The use of active personal dosemeters (APD) in interventional radiology was evaluated by Working Group 9 (Radiation protection dosimetry of medical staff) of the CONRAD project, which is a Coordination Action supported by the European Commission within its 6th Framework Program. Interventional radiology procedures can be very complex and they can lead to relatively high doses to personnel who stand close to the primary radiation field and are mostly exposed to radiation scattered by the patient. For the adequate dosimetry of these scattered photons, APDs must be able to respond to low-energy [10-100 keV] and pulsed radiation with relatively high instantaneous dose rates.

An intercomparison of five APD models deemed suitable for application in interventional radiology was organized in March 2007. The intercomparison used pulsed and continuous radiation beams, at CEA-LNHB (Saclay, France) and IRSN (Fontenay-aux-Roses, France), respectively. A specific configuration, close to the clinical practice was considered.

The reference dose, in terms of $\mathrm{Hp}(10)$, was derived from air kerma measurements and from the measured and calculated energy distribution of the scattered radiation field. Additional Monte Carlo calculations were performed to investigate the energy spectra for different experimental conditions of the intercomparison. The results of this intercomparison are presented in this work and indicate which APDs are able to provide a correct response when used in the specific low-energy spectra and dose rates of pulsed X-rays encountered in interventional radiology.
\end{abstract}




\section{INTRODUCTION}

Active personal dosemeters (APDs) are very efficient tools for the monitoring of occupational doses in many applications of ionising radiations. They offer an assessment of the dose in real time during exposure as well as selectable alarm levels, which are very useful to optimise procedures and to avoid unexpected or high doses. Interventional radiology operators belong to a specific worker category, which would benefit from a real time, accurate assessment of their dose. In fact, they can receive relatively high doses while standing close to the primary radiation field and being exposed to radiation scattered by the patient. For the adequate dosimetry of these scattered photons, APDs should be able to respond to low-energy [10$100 \mathrm{keV}]$ and pulsed radiation with relatively high instantaneous dose rates. Unfortunately, these are situations in which the current APD technology is not always adequate. This problem was clearly highlighted during an international intercomparison organised by EURADOS and IAEA ${ }^{(1)}$. Given this context, the use of APDs in interventional radiology was evaluated by Working Group 9 (Radiation protection dosimetry of medical staff) of the CONRAD project, which is a Coordination Action supported by the European Commission within its $6^{\text {th }}$ Framework Program.

An intercomparison of five APD models deemed suitable for application in interventional radiology was held in France during March 2007. The intercomparison used pulsed and continuous X-rays beams, available respectively at the Laboratoire National Henri Becquerel (LNHB) at CEA-LIST, the French National Metrology Laboratory for ionizing radiation in Saclay, and at a metrology laboratory of the Institute of Radiological Protection and Nuclear Safety (IRSN) in Fontenay-aux-Roses. Both laboratories are accredited according to the ISO standard $17025^{(2)}$. A specific configuration close to the clinical practice was chosen from the realistic irradiation fields designed by LNHB within the French national metrology work program. The reference dose $\mathrm{Hp}(10)$ was derived from air kerma measurements and from measured and calculated energy distributions of the scattered radiation field. Additional Monte Carlo calculations were performed by SCK $\cdot \mathrm{CEN}, \mathrm{CEA}$ and IRSN to determine the energy spectra of the different facilities.

The aim of the intercomparison was the identification of the APDs providing a correct response when used in the specific low-energy spectra and dose rates of pulsed X-rays encountered in interventional radiology. The detailed outcome of our investigation is presented hereafter, including the characteristics of the five selected APDs, a description of the irradiation facilities, the reference dose measurement and calculations. 


\section{MATERIALS AND METHODS}

\section{Characteristics of selected APDs}

In order to select the APD models for this study, we took into account the results from a previous intercomparison organized in 2005 by EURADOS and $\operatorname{IAEA}^{(1)}$, and the available usage data from different European countries. A pre-requisite for consideration was that the unit respond to photon energies down to $20 \mathrm{keV}$. Five APDs were finally selected for the study (Figure 1): DMC 2000XB (MGPI), EPD Mk2.3 (Siemens), DIS1-DIS100 (Rados), EDMIII (Panasonic) and PM1621A (Polimaster). Data provided by the manufacturers on the energy dependence of the response of these five APDs are reported in table 1.

\section{Description of facilities and test configuration}

The diagnostic pulsed X ray beam was generated with a MPH65 (GEMS) medical X-ray unit designed to generate only one pulse at a time. The continuous $\mathrm{X}$ ray beam was generated with a 100 kV (Philips) X-ray unit.

A specific configuration close to the clinical practice was considered (Figure 2 - table 2). Figures 3 and 4 show the experimental set up. All irradiations were carried out on a $30 \mathrm{~cm}$ x $30 \mathrm{~cm}$ x $15 \mathrm{~cm}$ ISO water slab phantom with PMMA walls (front wall $2.5 \mathrm{~mm}$ thick, other walls $10 \mathrm{~mm}$ thick) as defined in ISO $4037-3^{(3)}$. The APDs were irradiated one by one at the centre of the front face of the phantom, i.e. in the position for which the conventional true value of $\mathrm{Hp}(10)$ is known. Two dosemeters of each type were tested, except for the DIS-100 of which we had only one unit.

\section{Determination of reference $\mathrm{Hp}(10)$}

The reference value at point $\mathrm{X}$ (Figure 2) was based on measurements with a cavity ionisation chamber calibrated in the direct beam in terms of free-in-air air-kerma. Our measurements and Monte Carlo simulations indicated that the scattered beam had physical characteristics (mean, width, energy range, etc.) similar to those of the direct beam. Therefore, the same calibration factor was used for both direct and scattered radiation. It was also checked that, at point $\mathrm{X}, 98 \%$ of the photon fluence was within $\pm 30^{\circ}$ from the normal to the radiologistphantom $\left(0^{\circ}\right)$, and that multiple scattering between patient-phantom and radiologist-phantom was negligible. 
From the air kerma measured at point $\mathrm{X}$, without the radiologist-phantom, the reference personal dose equivalent, $H_{\mathrm{p}}\left(10,0^{\circ}\right)$, was calculated by multiplication with an appropriate conversion coefficient. This conversion coefficient was derived from the energy-dependent conversion coefficients from air-kerma to $H_{\mathrm{p}}\left(10,0^{\circ}\right)$ published in report 57 of the $\mathrm{ICRU}^{(4)}$ and averaged over the calculated scattered photon energy spectrum at point $\mathrm{X}$.

A study on the angle dependence of the scattered radiation was performed, calculating the spectra for different angles with respect to the normal axis of the surgeon phantom and considering the $\mathrm{H}_{\mathrm{p}}(10, \alpha) / \mathrm{H}_{\mathrm{p}}\left(10,0^{\circ}\right)$ coefficients in the ICRU report $57^{(4)}$. We could conclude, however, that this study changed the conversion coefficient $H_{p}(10) / K_{\text {air }}$ by less than $2 \%$.

The scattered energy spectra were measured at each facility with a CdTe XR-100T spectrometer (Amptek), whose energy dependence had been previously determined at LNE LNHB. The scattered spectra were also determined by independent Monte Carlo calculations. The source photon spectra of the X-ray generator of each facility were calculated using the software XCOMP5 ${ }^{(5)}$. The following X-ray transport through the water-slab patient-phantom was calculated by IRSN using MCNPX $2.5 \mathrm{f}^{(6)}$, by CEA using MCNP4C2 ${ }^{(7)}$ and PENELOPE $2006^{(8)}$, and by SCK $\cdot$ CEN using MCNPX 2.5.0 ${ }^{(6)}$.

In Figure 5, calculated and measured energy spectra are shown and compared: their clear similarity was taken as a validation of our approach. It may be observed that this scattered radiation field appears fairly similar to the W60 quality from the ISO 4037-1 standard $^{(9)}$. The $\mathrm{H}_{\mathrm{p}}\left(10,0^{\circ}\right) / \mathrm{K}_{\mathrm{air}}$ conversion coefficient that we used for this field was $1.53 \mathrm{~Sv} / \mathrm{Gy}$, i.e., a mean value between the estimates from IRSN (1.53), CEA-LNHB (1.52) and SCK•CEN (1.54).

The difference between the estimates from the different laboratories are due to statistical uncertainties and to differences between computation codes and cross section data used in the simulations.

Since the main component of the uncertainty on the reference value comes from the conversion coefficient from air kerma to personal dose equivalent (2\%), a first evaluation of the standard uncertainty on the reference value of the personal dose equivalent is $3 \%$. 


\section{RESULTS}

\section{Response of APDs}

The responses of the APDs are presented in tables 3 and 4. It is noticeable that four dosemeters over five are sensitive to the single pulse radiation used for this intercomparison. Besides, the requirement of IEC standard ${ }^{(10)}$ in terms of energy response is not fulfilled for only one dosemeter (DIS 100). The standard deviations observed were between 0.3 and $1.5 \%$ for a single APD (repeated irradiations) and less or equal to $5 \%$ for two APDs of the same type ( $14 \%$ was observed for one type), but one has to keep in mind that only two dosemeters of the same type were tested.

\section{CONCLUSION}

The results of this test show first that four dosemeters over five are sensitive to the single pulse radiation used for this intercomparison. Therefore, it is recommended to check the dosemeter when receiving them since the response can vary drastically (up to $14 \%$ ) from one dosemeter to another of the same type.

Moreover, the capability of measuring the pulsed radiation depends on the principle of detection of each dosemeter. For single-pulse radiation fields, they can be blind. Additional work is required to test the dosemeters in front of multi-pulsed radiation fields.

\section{AKNOWLEDGEMENTS}

This work was done in the framework of EURADOS and the CONRAD project, a Coordination Action supported by the European Commission. 


\section{REFERENCES}

1. IAEA-EURADOS Report. Intercomparison on measurements of the quantity personal dose equivalent $\mathrm{Hp}(\mathrm{d})$ by active personal dosimeters. In press.

2. International Organization for Standardization (ISO). General requirements for the competence of testing and calibration laboratories ISO 17025 (2005).

3. International Organization for Standardization (ISO). $\mathrm{X}$ and gamma reference radiation for calibrating dosemeters and doserate meters and for determining their response as a function of photon energy - Part 3: Calibration of area and personal dosemeters and the measurement of their response as a function of energy and angle of incidence. International Standard ISO 4037 (Geneva: ISO) (1999).

4. International Commission on Radiation Units and Measurements (ICRU). Conversion Coefficients for use in Radiological Protection Against External Radiation. ICRU Report 57 (Bethesda, MD 20814: ICRU Publications) (1998).

5. Nowotny, R. and Hofer, A., XCOMP5, Program for calculating diagnostic X-ray spectra, RoeFo, Fortschr. Geb. Roentgenstr. Nuklearmed. 142, 685-689 (1985).

6. MCNPX Extensions Version 2.5.0. Los Alamos National Laboratory, LA-UR-052675 (2005).

7. Breismeister, JF. (ed). MCNP ${ }^{\mathrm{TM}}$ - A general Monte Carlo N-particle transport code, version 4C, Los Alamos National Laboratory. Report LA-13709-M (2000).

8. Salvat, F., Fernández-Varea, JM., Sempau J. PENELOPE 2006: A Code System for Monte Carlo Simulation of Electron and Photon Transport, Workshop Proceedings Barcelona, Spain 4-7 July 2006, OECD 2006 NEA No. 6222, Nuclear energy agency organisation for economic co-operation and development (2006).

9. International Organization for Standardization (ISO). $\mathrm{X}$ and gamma reference radiation for calibrating dosemeters and doserate meters and for determining their response as a function of photon energy - Part 1: Radiation characteristics and production methods. International Standard ISO 4037 (Geneva: ISO) (1996).

10. International Electrotechnical Commission (IEC). Radiation Protection Instrumentation. Measurement of Personal Dose Equivalent $\mathrm{Hp}(10)$ and $\mathrm{Hp}(0.07)$ for X, Gamma, Neutron and Beta radiation: Direct Reading Personal Dose Equivalent and monitors. IEC 61526:2 (2005). 
Table 1. Photon energy response characteristics of tested APDs as provided by the manufacturer

\begin{tabular}{cccc}
\hline \multirow{2}{*}{ APD type and manufacturer } & \multicolumn{2}{c}{ Energy response } & Deviation (\%) \\
& Emin (keV) & Emax (keV) & \\
\hline DMC 2000XB - MGPI & 20 & 6000 & 30 \\
EPD Mk2.3 - Siemens & 15 & 7000 & 20 \\
DIS1-DIS100- Rados & 15 & 9000 & 30 \\
EDM III - Panasonic & 20 & 1500 & 10 \\
PM1612A - Polimaster & 10 & 20000 & 15 \\
\hline
\end{tabular}


Table 2. Beam parameters used for the intercomparison

\begin{tabular}{|c|c|c|}
\hline & Continuous field & Pulsed field \\
\hline Tube voltage $(\mathrm{kVp})$ & \multicolumn{2}{|c|}{70} \\
\hline Total filtration & \multicolumn{2}{|c|}{$4.5 \mathrm{~mm} \mathrm{Al}+0.2 \mathrm{~mm} \mathrm{Cu}$} \\
\hline Tube load (mA) & 20 & 640 \\
\hline Pulse width (ms) & - & 100 \\
\hline Field shape & circular & square \\
\hline $\begin{array}{l}\text { Field size at } 95 \mathrm{~cm} \\
\text { from source }(\mathrm{cm})\end{array}$ & diameter $=19.3$ & edge $=17$ \\
\hline $\begin{array}{l}\text { Angle of tungsten } \\
\text { anode }\left(^{\circ}\right)\end{array}$ & 20 & 12.5 \\
\hline
\end{tabular}


Table 3. Response of APDs in terms of $\operatorname{Hp}\left(10,0^{\circ}\right)$

\begin{tabular}{cccccccc}
\hline Mode & $\begin{array}{c}\text { Reference } \\
\text { Hp(10) }\end{array}$ & $\begin{array}{c}\text { DMC } \\
\text { 2000XB }\end{array}$ & $\begin{array}{c}\text { EPD } \\
\text { Mk2.3 }\end{array}$ & DIS1 & DIS100 & PM 1621A & EDM III \\
\hline Continuous & $228 \mu \mathrm{Sv}$ & 1.04 & 0.72 & 0.64 & 0.54 & 1.00 & 0.87 \\
Pulsed & $122 \mu \mathrm{Sv}$ & 1.14 & 0.78 & 0.73 & 0.58 & 0.01 & 1.07 \\
\hline
\end{tabular}


Table 4. Angular response of APDs in terms of $\operatorname{Hp}(10, \alpha) / \operatorname{Hp}\left(10,0^{\circ}\right)$

\begin{tabular}{ccccccccc}
\hline \multirow{2}{*}{ Angle } & $\begin{array}{c}\text { W-60 (ISO } \\
\mathbf{4 0 3 7})^{*}\end{array}$ & Mode & $\begin{array}{c}\text { DMC } \\
\mathbf{2 0 0 0 X B}\end{array}$ & $\begin{array}{c}\text { EPD } \\
\text { Mk2.3 }\end{array}$ & DIS1 & DIS100 & PM 1621A & EDM III \\
\hline \multirow{2}{*}{$30^{\circ}$} & \multirow{2}{*}{0.96} & Continuous & 1.00 & 0.98 & 0.92 & 1.00 & 0.93 & 1.10 \\
& & Pulsed & 0.96 & 0.96 & 0.92 & 0.97 & - & 1.05 \\
$60^{\circ}$ & \multirow{2}{*}{0.76} & Continuous & 0.81 & 0.84 & 0.80 & 0.86 & 0.53 & 0.83 \\
& & Pulsed & 0.65 & 0.71 & 0.76 & 0.74 & - & 0.66 \\
\hline
\end{tabular}

* These values has been taken from ISO 4037 for quality W-60 which is similar to the spectra used for this study 


\section{FIGURE CAPTIONS}

Figure 1. Active personal dosemeters tested for this intercomparison

Figure 2. Configuration used for the intercomparison.

Figure 3. Experimental sep up using the diagnostic $\mathrm{X}$ ray facility at CEA-LNHB France

Figure 4. Experimental sep up using continuous X-rays facility at IRSN France

Figure 5. Measured and calculated energy spectra at the position of the staff 
Figure 1

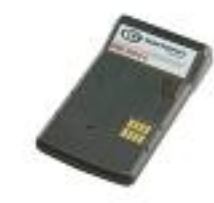

MGPI

DMC $2000 \times$

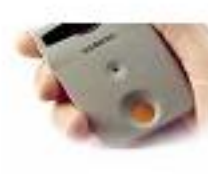

SIEMENS EPD Mk2.3
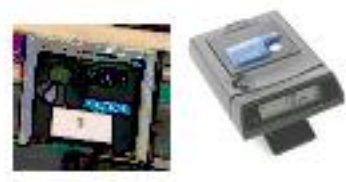

RADOS DIS1 - DIS100
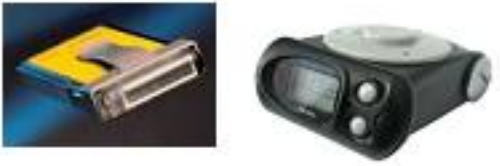

PANASONIC EDHI III
OLIMASTER

PH1621A 
Figure 2

a) free in air

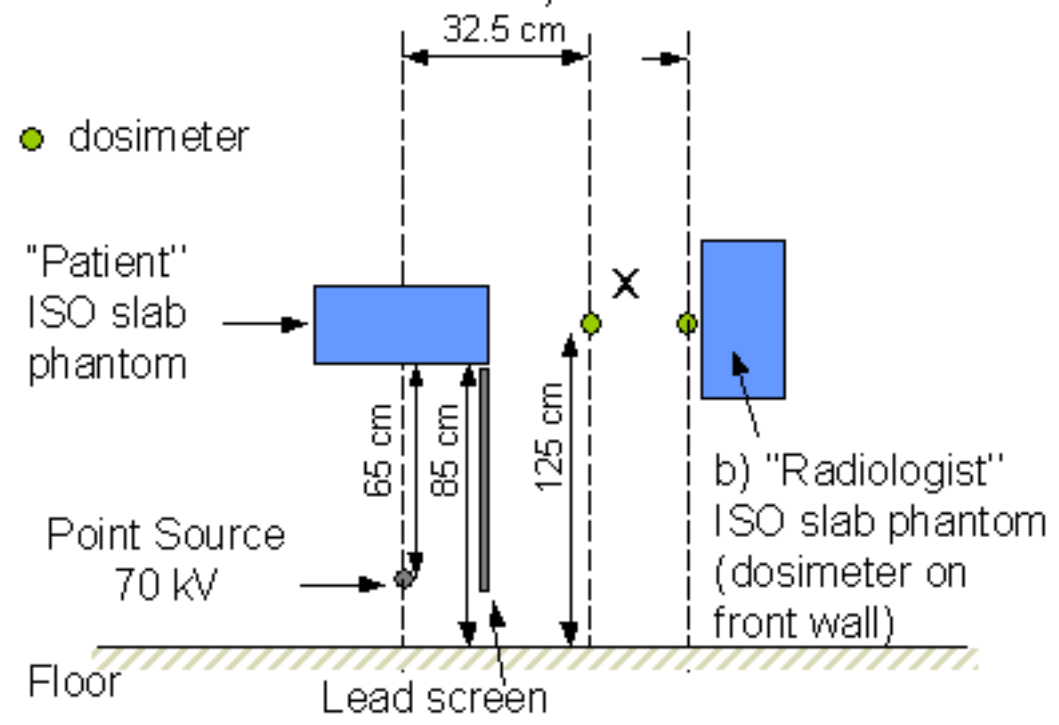


Figure 3

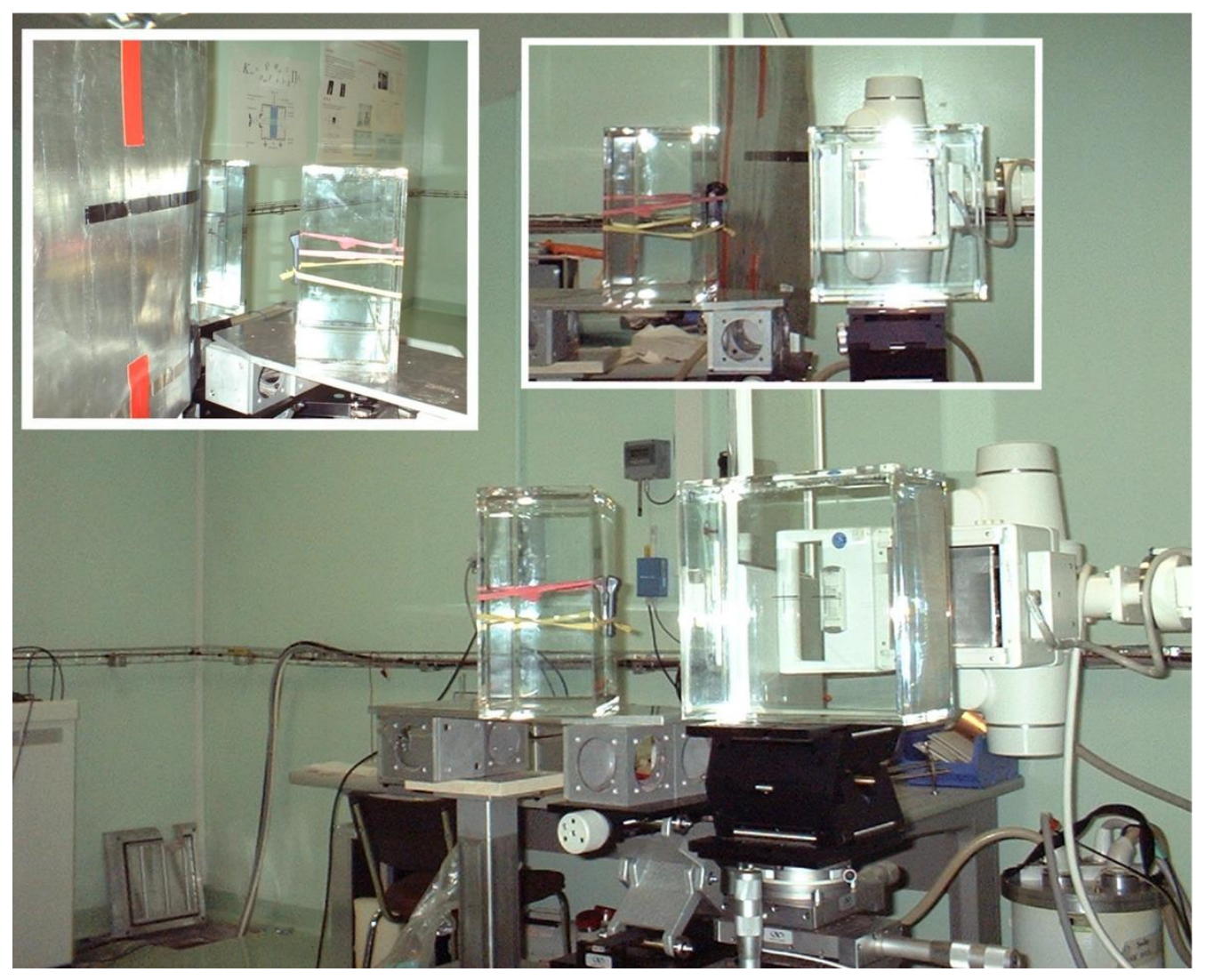


Figure 4

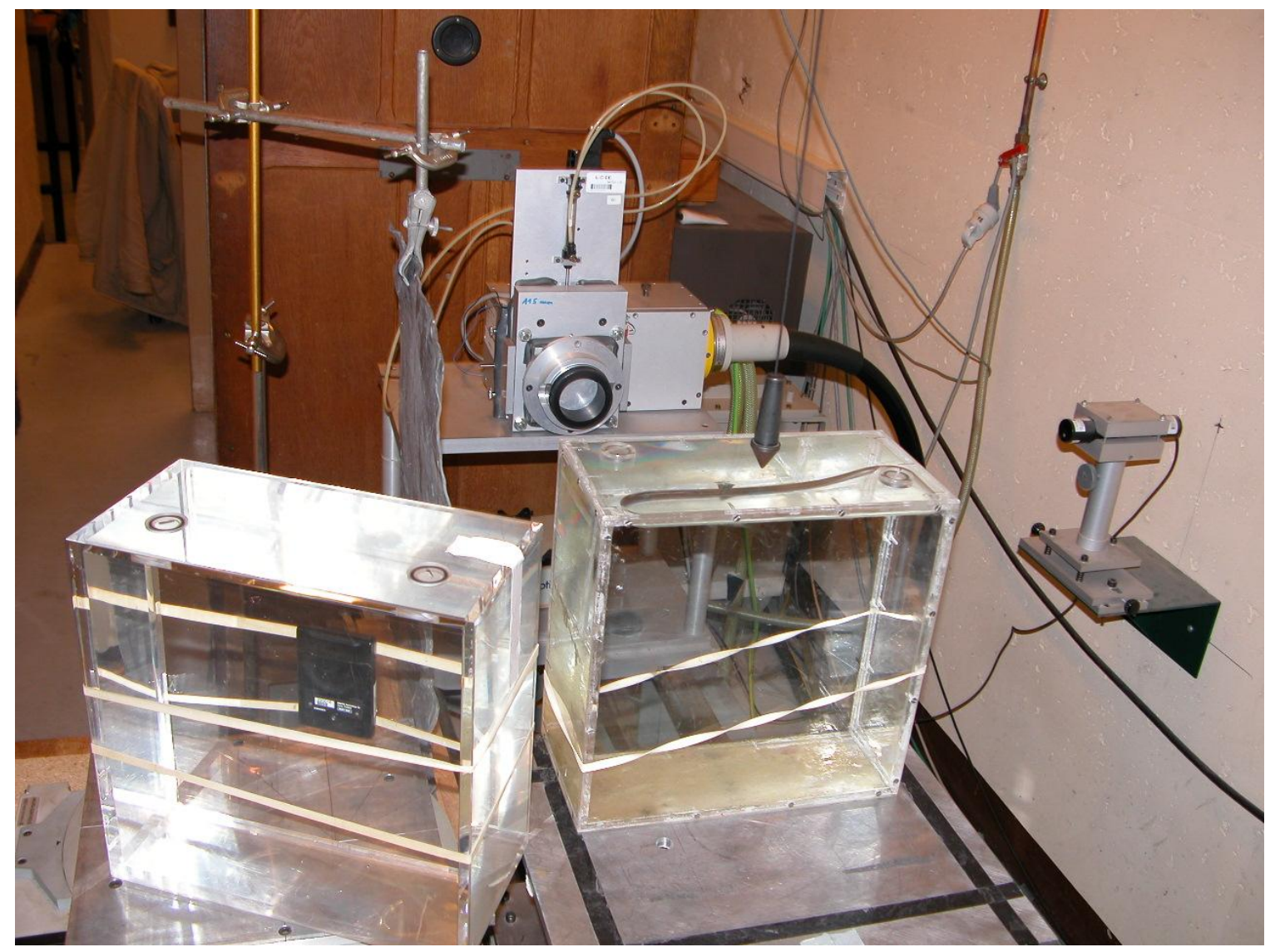


Figure 5

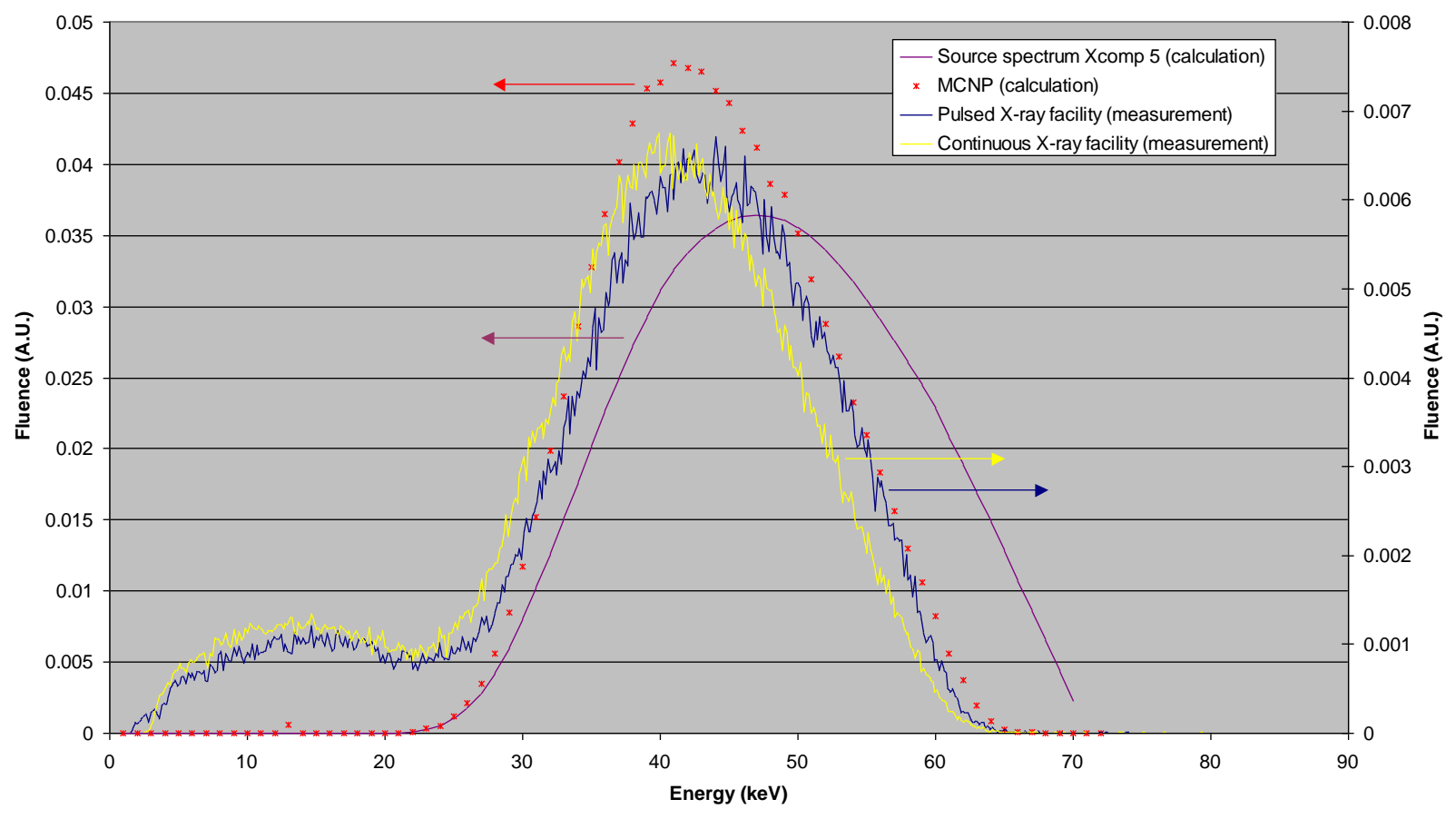

